\title{
The dependency of geoengineered sulfate aerosol on the emission strategy
}

\author{
U. Niemeier,* H. Schmidt and C. Timmreck \\ Max Planck Institute for Meteorology, Bundesstr. 53, Hamburg, Germany
}

* Correspondence to:

U. Niemeier, Max Planck

Institute for Meteorology,

Bundesstr. 53, 20246 Hamburg,

Germany.

E-mail:

Ulrike.Niemeier@zmaw.de

Received: 25 February 2010

Revised: 27 August 2010

Accepted: 7 September 2010

\begin{abstract}
The climatic effect of geoengineered stratospheric sulfate aerosol depends on the strategy for sulfur emission that determines the microphysical evolution of the resulting sulfate layer, in particular the radius and radiative impact of the aerosols. Simulations with a threedimensional general circulation model (GCM), including an aerosol microphysical model, show e.g. decreasing sulfate lifetime with increasing emission rate. Furthermore, scenarios that differ with respect to location, local and temporal distribution and chemical composition of the emissions are studied. The study shows detailed information on particle radius, sulfate burden and radiative impact for these scenarios. Copyright $($ C 2010 Royal Meteorological Society
\end{abstract}

Keywords: geoengineering; sulfate aerosol; aerosol microphysics; stratosphere

\section{Introduction}

There is increasing scientific evidence that the anthropogenic emission of greenhouse gases has a significant impact on the Earth's climate (IPCC, 2007). Despite attempts to limit anthropogenic emissions, carbon dioxide concentrations in the atmosphere have continued to increase. Consequently, a debate has started on technical methods to limit global warming, usually referred to as 'geoengineering'. One of the proposed techniques, suggested by Budyko (1977) and Crutzen (2006), follows the natural example of volcanic eruptions emitting large amounts of sulfur dioxide $\left(\mathrm{SO}_{2}\right)$ into the stratosphere. Chemical and microphysical reactions cause the formation of sulfate aerosols that reduce the incoming solar radiation. It is however unclear, as to what extent this volcanic example can be used as analogue for the effect of geoengineered aerosol because of possible differences in the aerosol size distributions and radiative properties resulting from different emission patterns.

Recently, several studies have estimated the climatic effect of geoengineered aerosols by performing climate model simulations with prescribed particle size and relatively coarse assumptions for the particle evolution (Rasch et al., 2008; Robock et al., 2008; Tilmes et al., 2009). The first study with a more comprehensive, albeit two-dimensional, sectional aerosol microphysical model has been performed by Heckendorn et al. (2009). One important result of this study is that the particle size distribution of the aerosol cloud depends strongly on the magnitude of the injections. Our study can be seen as an extension of the one by Heckendorn et al. (2009) using a three-dimensional modal aerosol model and allowing for dynamical feedbacks on the particle distribution. The particle size is a crucial parameter for the effectiveness of stratospheric aerosols as it influences its absorption and scattering properties. For the temporal development of the aerosol size distribution, the injection strategy is likely of importance. Sulfur could be injected at different rates and different heights, continuously or pulsed, in a single small area or distributed along the Equator. To study the impact of different emission strategies on the evolution of the sulfate aerosol and in particular the resulting particle radius and radiative impact, we have performed simulations with the middle atmosphere version of the general circulation model (GCM) ECHAM5 (Roeckner et al., 2006) interactively coupled to a modified version of the aerosol microphysical model, HAM (Stier et al., 2005).

It is assumed that one significant side effect from sulfate geoengineering is additional stratospheric ozone depletion. In contrast to the work of Heckendorn et al. (2009), our model does not include stratospheric ozone chemistry. However, we analyze the surface area density (SAD) of geoengineered aerosols as an indicator for its ozone depletion potential (Tilmes et al., 2008).

\section{Model description and setup of simulations}

The simulations were performed with the middle atmosphere model MAECHAM5 (Giorgetta et al., 2006) in a version with spectral truncation at wavenumber 42 (T42) and 39 vertical layers up to $0.01 \mathrm{hPa}$. The GCM solves prognostic equations for vorticity, divergence, surface pressure and temperature. The aerosol microphysical model HAM was interactively coupled to the GCM. HAM calculates the formation of sulfate aerosol which includes nucleation, accumulation, 
condensation and coagulation processes. M7 (Vignati et al., 2004), the microphysical core of HAM, was modified to allow for a better representation of stratospheric sulfur aerosol according to box-model studies for large volcanic eruptions (Kokkola et al., 2009). The changes include a reduction to three modes (nucleation, Aitken and accumulation), and a smaller standard deviation of the accumulation mode $(\sigma=1.2$ instead of 1.59). Details on sulfur chemistry and prescribed gaseous species concentrations are described by Niemeier et al. (2009). The simulations include only sulfate aerosol. Besides the geoengineered sulfur, only dimethyl-sulfide (DMS) and carbonyl-sulfide emissions are included in the simulations.

The model setup has been used in previous studies on the climatic impact of volcanic eruptions and compared in detail with measurements after the Mount Pinatubo eruption (Niemeier et al., 2009). The results show good agreement with measurements. We see a slight overestimation of the poleward transport, simulated particle radius, and aerosol optical depth (AOD).

To study the dependence of the particle size distribution and the effects of geoengineered sulfate aerosol on the amount of injected $\mathrm{SO}_{2}$ a series of numerical experiments were designed with continuous emissions of 1, 2, 4 and $8 \mathrm{Mt}(\mathrm{S}) / \mathrm{y}$. In most experiments, sulfate was injected into one grid box with the size of $2.8^{\circ} \times$ $2.8^{\circ}$ centered at $1.4^{\circ} \mathrm{N} 121^{\circ} \mathrm{E}$, a similar position as used by Robock et al. (2008). We conducted experiments with emissions at $60 \mathrm{hPa}(\sim 19 \mathrm{~km})$ height (Expo60) and $30 \mathrm{hPa}(\sim 25 \mathrm{~km})$ height (Expo30). The lower injection level, $60 \mathrm{hPa}$, can still be reached by some planes. For the higher level, $30 \mathrm{hPa}$, a higher lifetime of aerosols is expected. Robock et al. (2009) show options to release particles even at such high stratospheric altitudes. Three further sensitivity experiments were performed for the $4 \mathrm{Mt}(\mathrm{S}) / \mathrm{y}$ emission scenario: $\mathrm{SO}_{2}$ was emitted twice a year in pulses of 30 days each (Epulse) into the box given above and emitted in one latitude band (Elat) of the width of one grid box, along the Equator. In experiment (Eh2so4), emissions into one grid box are assumed to be in the form of $\mathrm{H}_{2} \mathrm{SO}_{4}$ instead of the precursor gas $\mathrm{SO}_{2}$, as suggested by Pierce et al. (2010). All presented results are averaged over 3 years of a steady-state sulfate layer.

\section{Results}

\section{I. Role of emission rate}

The simulated sulfate load depends strongly on the emission rate (Figure 1). For emissions at $60 \mathrm{hPa}$ (Exp60), maximum concentration and global burden increase by a factor of $1.8-1.9$, when doubling $\mathrm{SO}_{2}$ injection. Accordingly, the lifetime decreases with increasing emission strength. For emission rates of 1, 2, 4 and $8 \mathrm{Mt}(\mathrm{S}) / \mathrm{y}$, we obtain lifetimes of 0.91 ,
$0.85,0.80$ and 0.74 years, respectively. The size of the particles increases with increasing sulfate load (Figure 2(b)): from an effective radius of $0.26 \mu \mathrm{m}(1$ $\mathrm{Mt}(\mathrm{S}) / \mathrm{y})$ to $0.4 \mu \mathrm{m}(8 \mathrm{Mt}(\mathrm{S}) / \mathrm{y})$. The calculated burden and its dependency on the emission rate are similar to the values obtained by Heckendorn et al. (2009). However, their global burden (Figure 2(a)) increases less strongly with the emission rate, possibly due to differences in the particle sizes resulting from the use of different aerosol models (sectional $v s$ modal). Rasch et al. (2008) show global burdens for emission rates of 1 and $2 \mathrm{Mt}(\mathrm{S}) / \mathrm{y}$, which are about a factor of 2 larger than our values. This is likely due to their assumption of fixed, uniform radii, which prevent the growth of large, fast sedimenting particles.

The annually averaged aerosol distributions shown in Figure 1 result in an almost zonal distribution of AOD (not shown). The AOD is also characterized, besides the increase with increasing injection rate, by rather symmetric meridional distributions with secondary maxima in the mid-latitudes (Figure 3, bottom). This pattern is mirrored by the resulting aerosol radiative forcing shown as the annual mean clear-sky shortwave (SW)-flux anomaly in Figure 3 (top). Flux anomalies are computed in the model via a twofold calculation of the radiation, with and without aerosols, at each radiation time step. The pronounced mid-latitude maxima are mainly summertime effects. The low values at the poles are the impact of seasonal solar flux conditions. Although during two Summer months the values close to the poles are in the range of tropical values, they are zero between late Autumn and early Spring resulting in low annual mean values. SW-flux (all-sky) anomalies show a strong single maximum in the Tropics. Differences in the clear-sky forcing are related to cloud albedo effects.

Meridional transport in the stratosphere is caused by the Brewer-Dobson circulation (BDC). Apparently, the strength of the BDC differs between the models used for geoengineering studies, causing different results for AOD and SW-fluxes. Heckendorn et al. (2009) show similar clear-sky SW-flux maximum values, but much lower ones in the mid-latitudes, which is likely due to very weak meridional transport. Pattern and values of downward SW-flux of Robock et al. (2008), in a study with fixed aerosol size, are comparable to our results in mid-latitudes. Similar to MAECHAM5, they indicate a slightly stronger meridional transport compared to measurements after the Mount Pinatubo eruption. These differences are reflected in the global SW radiative forcing (Figure 2(c)). SAD increases with increasing emissions and are slightly stronger at high latitudes than in the Tropics (Figure 4). Values in Heckendorn et al. (2009) are similar in the tropical maxima, but much lower poleward.

\subsection{Role of emission height}

The cases with emissions at $30 \mathrm{hPa}$ (Exp30) shows, compared with the same emission rates at $60 \mathrm{hPa}$, 

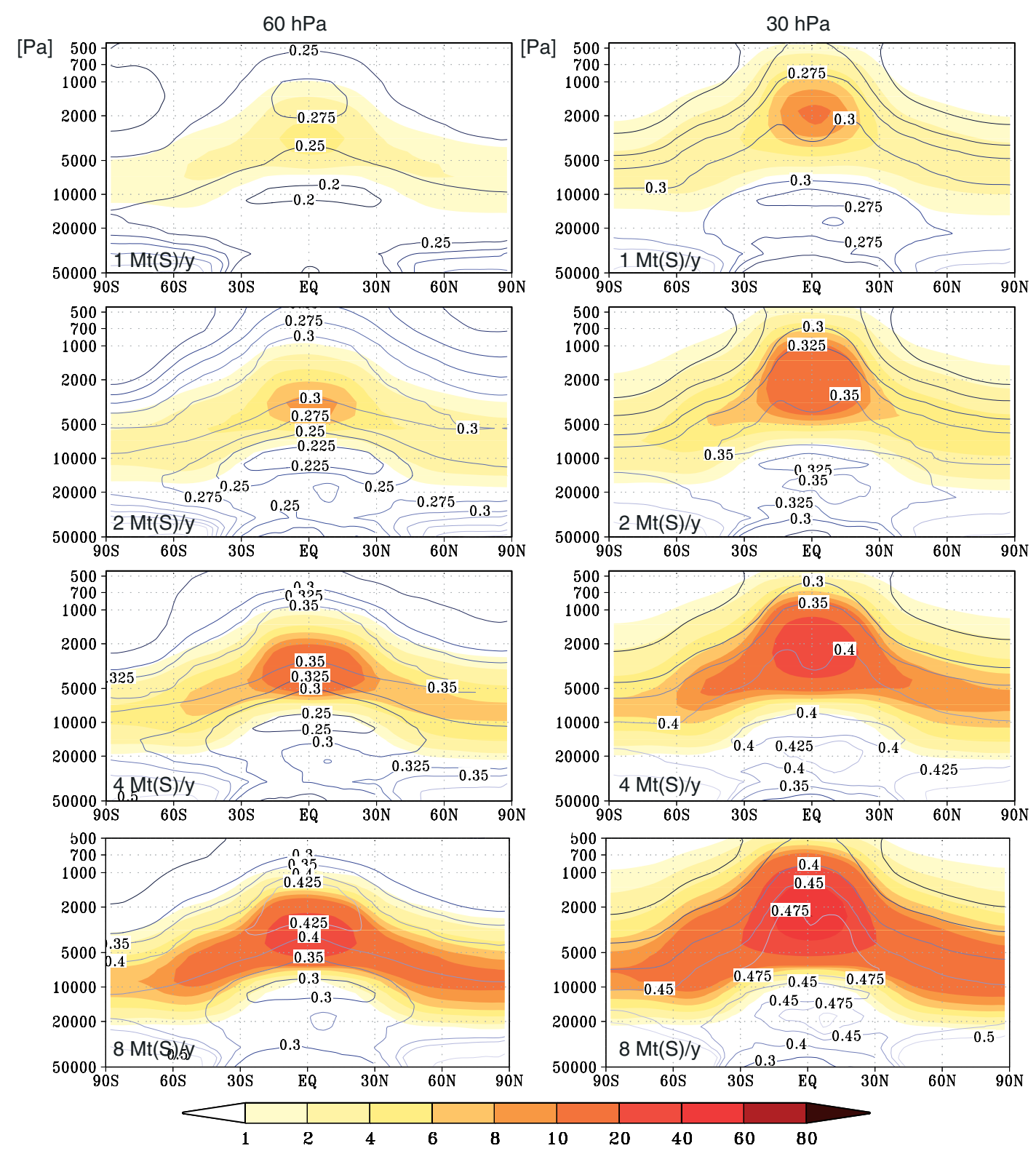

Figure I. Zonal mean sulfate mass-mixing ratio (ppb) (color shading) and effective radius ( $\mu \mathrm{m})$ (contour lines) for different emission rates and heights (annual mean).

higher concentrations (Figure 2(a)) and about 10-20\% larger particle radii (Figure 2(b)). A longer sedimentation path and slightly less poleward transport, indicated by more pronounced maxima of AOD and SWflux in the equatorial region (Figure 3, right), contributes to a longer aerosol lifetime in the stratosphere. The global burden is increased by a factor of 1.7, 1.6, 1.5 and 1.37 for emissions of $1,2,4$ and 8 $\mathrm{Mt}(\mathrm{S}) / \mathrm{y}$, respectively, compared to the $60 \mathrm{hPa}$ case. The $8 \mathrm{Mt}(\mathrm{S}) / \mathrm{y}$ rate yields particles similar in effective radius (10-20\% smaller) compared to measurements taken after the Mount Pinatubo eruption (Ansmann et al., 1997). For lower emission rates, the particles have an even smaller size $(0.25-0.4 \mu \mathrm{m})$, confirming assumptions of Crutzen (2006).

The SAD is higher in the $60 \mathrm{hPa}$ emission case (Figure 2(d)) caused by a higher number of fine nucleation particles (about ten times) in the Tropics. The relation between SAD and all-sky SW-flux anomaly highlights the higher ratio of effectiveness (radiative forcing) to risk (ozone depletion) of emissions at higher levels.

\subsection{Role of emission period}

To study the impact of the emission period we performed a sensitivity study with pulsed $\mathrm{SO}_{2}$ emissions equivalent to $4 \mathrm{Mt}(\mathrm{S}) / \mathrm{y}$ at $60 \mathrm{hPa}$ (Epulse). Results are very similar compared to continuous emissions. Yearly averaged global sulfate burden and the SW-fluxes are almost identical (Figure 2, red circle). Particle size is $0.02 \mu \mathrm{m}$ smaller.

\subsection{Role of emission area}

Simulation Elat with $\mathrm{SO}_{2}$ emission homogeneously distributed along the Equator shows a different picture 

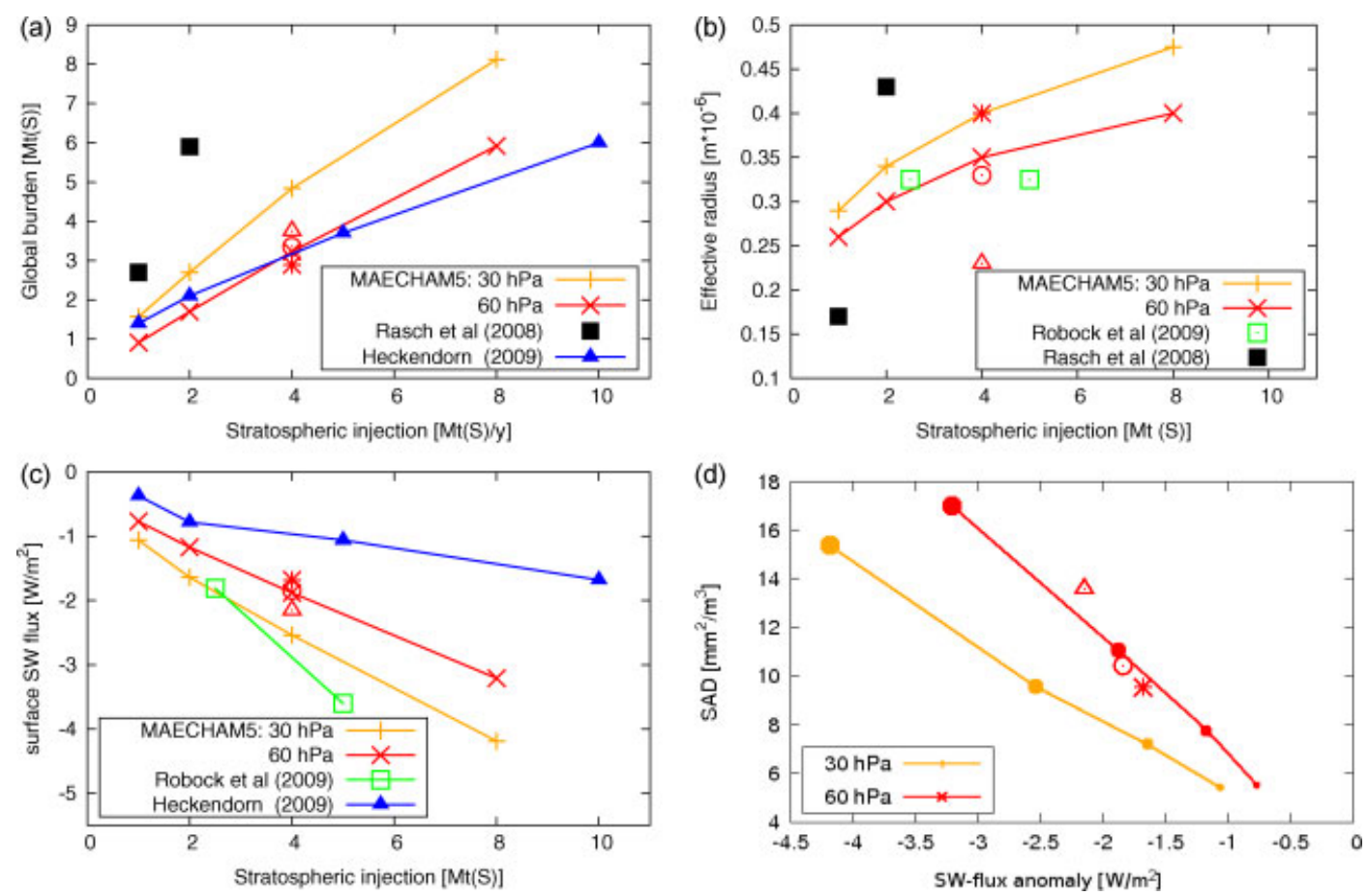

Figure 2. Global sulfate burden calculated in different studies (a) and effective wet radius $(\mu \mathrm{m})$ of sulfate particles in the center of the sulfate layer (b). Red signs indicate simulation $c$ using pulsed emissions (circle), simulation Elat with emissions along the Equator (star) and simulation Eh2so4 (triangle). Globally averaged SW-flux anomaly (all-sky) $\left(\mathrm{W} \mathrm{m}^{-2}\right.$ ) (c) and SW-flux (all-sky) versus SAD $\left(\mathrm{mm}^{2} \mathrm{~m}^{-3}\right)$, global average over the vertical levels between 200 and $10 \mathrm{hPa}(\mathrm{d})$. The increasing size of the bullets represents the increasing emission rates $(\mathrm{I}, 2,4$ and $8 \mathrm{Mt}(\mathrm{S}) / \mathrm{y})$.

compared to the simulations with grid-box emissions. The particle size increases to $0.4 \mu \mathrm{m}$ (Figure 2(b), red asterisks), causing stronger sedimentation and lower sulfate concentrations, lower AOD and up to $0.4 \mathrm{~W} / \mathrm{m}^{2}$ lower SW-fluxes (all-sky) (Figure 3, light red lines).

Emitted into one grid box, $\mathrm{SO}_{2}$ and $\mathrm{H}_{2} \mathrm{SO}_{4}$ values are larger between 0 and $120^{\circ} \mathrm{E}$ than farther east of the emission area. The longitudinal emissions cause a smaller $\mathrm{SO}_{2}$ emission flux and equally distribute $\mathrm{H}_{2} \mathrm{SO}_{4}$ in low concentrations, which lead to condensation on existing particles rather than to nucleation, causing low particle numbers with an increased radius. Therefore, a global spread of the injection band seems to be contra productive for geoengineering purposes. This result adds the third dimension to the results of Heckendorn et al. (2009), where emissions had to be assumed as zonal homogeneous.

\subsection{Role of emitted species}

The opposite effect shows simulation Eh2so4, where sulfur is assumed to be emitted in the form of $\mathrm{H}_{2} \mathrm{SO}_{4}$ rather than $\mathrm{SO}_{2}$. The high initial $\mathrm{H}_{2} \mathrm{SO}_{4}$ concentration favours nucleation over condensation, causing a high amount of small particles, less effective coagulation and therefore more but smaller particles in the accumulation mode $(0.23 \mu \mathrm{m})$. Therefore, the lifetime is increased by 1.5 months and radiative forcing is up to $20 \%$ stronger in the Tropics (Figure 3, dark red lines). The AOD increased mainly in the Tropics.

\subsection{Role of dynamical feedback}

As described by Niemeier et al. (2009) for the case of volcanic eruptions, the additional heating due to absorption by sulfate aerosol may lead to increased upwelling. This should lead to an increased aerosol lifetime. To quantify this feedback and the possible effect on the radiative forcing, an additional experiment (with $4 \mathrm{Mt}(\mathrm{S}) / \mathrm{y}$ emitted at $60 \mathrm{hPa}$ ) was performed with the stratospheric aerosol heating switched off.

Figure 5 shows an increase in the sulfate massmixing ratio up to $1 \mathrm{ppb}(\sim 20 \%)$ in the upper part of the sulfate layer and a slight decrease in the lower part caused by the dynamical feedback when the aerosol heating is taken into account. The residual (upward) vertical velocity in the equatorial stratosphere is increased by about $5-10 \%$ as a result of the radiative heating.

\section{Conclusions}

Sulfur emission into the stratosphere has been suggested as a geoengineering option to cool the Earth. The presented model study tries to estimate the efficiency of different emission strategies by studying the microphysical behaviour of the resulting aerosol. Our numerical experiments confirm an important earlier result obtained by Heckendorn et al. (2009). An increase in the $\mathrm{SO}_{2}$ emission rate does not lead to a similar increase in the radiative forcing because 
$60 \mathrm{hPa}$
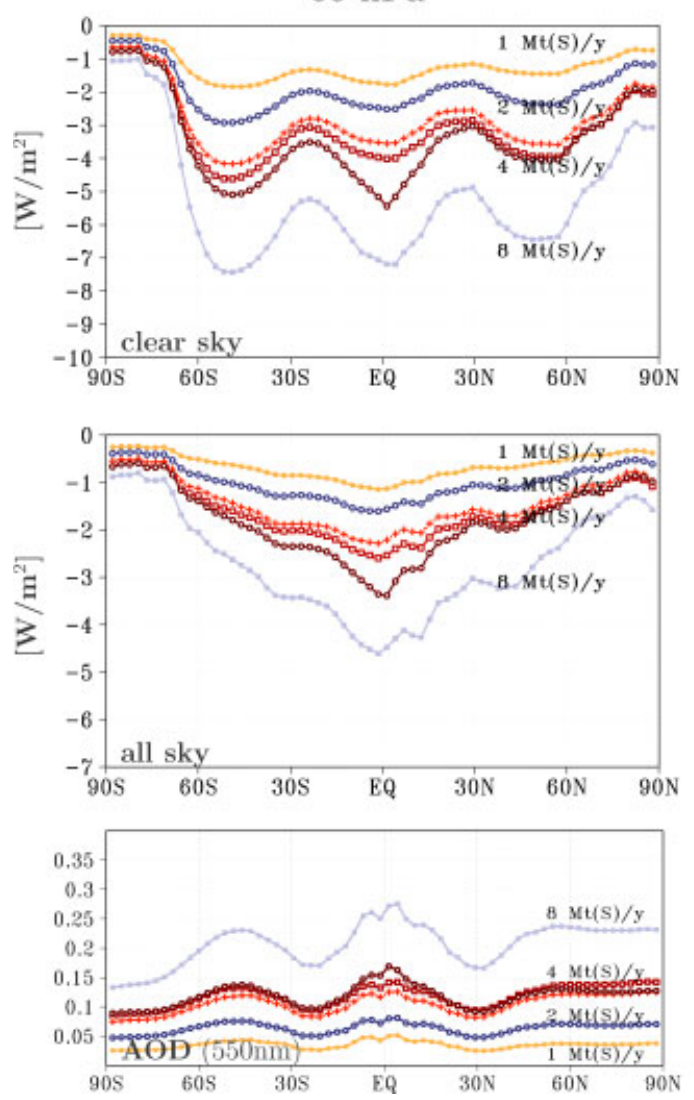

$30 \mathrm{hPa}$
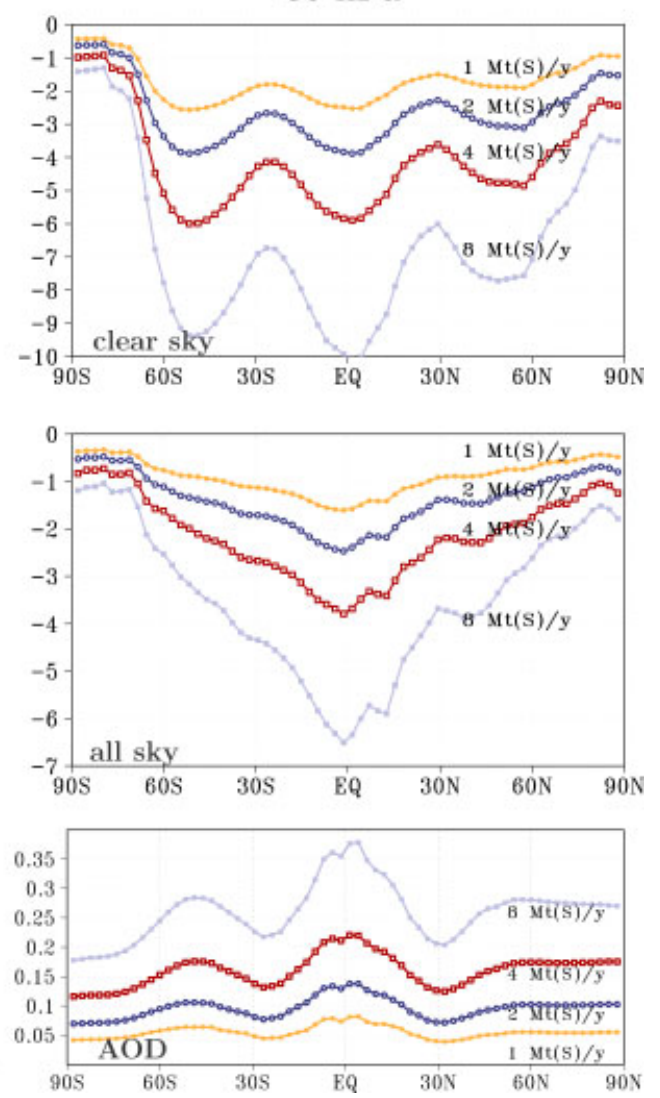

Figure 3. Annual and zonal mean of SW-flux anomaly $\left(\mathrm{W} \mathrm{m}^{-2}\right)$ at the surface for clear-sky (top) and all-sky (with clouds) conditions (middle) and aerosol optical depth (bottom). Contours are given for emission rates of I (orange), 2 (blue), 4 (red) and $8 \mathrm{Mt}(\mathrm{S}) / \mathrm{y}$ (gray), simulation Elat (red cross) and simulation Eh2so4 (dark red). All results are given for emissions at $60 \mathrm{hPa}$ (left) and $30 \mathrm{hPa}$ (right).

$1 \mathrm{Mt}(\mathrm{S}) /$ year

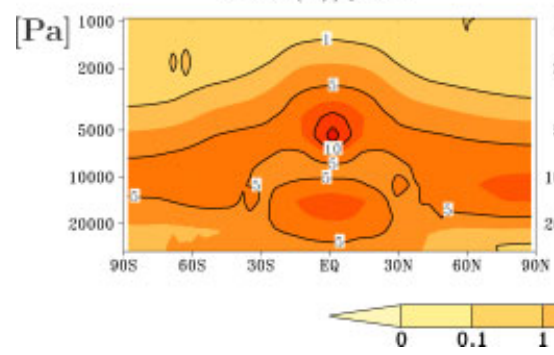

$2 \mathrm{Mt}(\mathrm{S}) /$ year

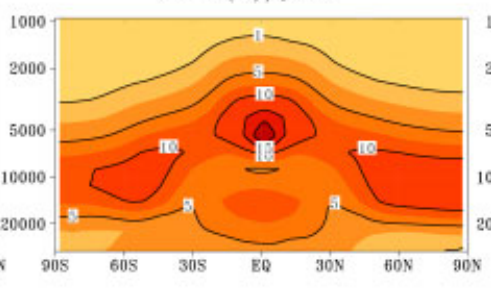

$4 \mathrm{Mt}(\mathrm{S}) /$ year

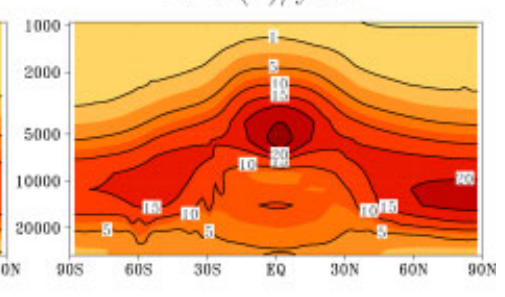

Figure 4. $\mathrm{SAD}\left(\mathrm{mm}^{2} / \mathrm{m}^{3}\right)$ for $\mathrm{SO}_{2}$ emissions at $60 \mathrm{hPa}$.

the size of the aerosols increases and, accordingly, its lifetime decreases. Studies that use fixed aerosol parameters independent of the emission rate may therefore overestimate the radiative forcing at high emission rates.

Further, our study shows that the lifetime of the particles depends on emission height. The calculated burden for emissions at $30 \mathrm{hPa}$ is almost twice the burden calculated for the same emission strength but at $60 \mathrm{hPa}$, resulting in a significantly larger forcing despite the growth of larger particles. A higher injection level results in a smaller SAD but the maximum $\mathrm{SAD}$ is located at a similar height as the maximum of the ozone concentration. Studies with included chemistry models may show whether the ozone-depletion changes with changing emission height. However, emission at $30 \mathrm{hPa}$ would probably be technically more challenging than at $60 \mathrm{hPa}$. Direct emissions of $\mathrm{H}_{2} \mathrm{SO}_{4}$ instead of $\mathrm{SO}_{2}$ decreases the availability of $\mathrm{H}_{2} \mathrm{SO}_{4}$ outside the emission region and increases the lifetime of the sulfate by about $15 \%$. Because of using a three-dimensional aerosol model, we could compare the effect of emissions in one single grid box versus emissions along the Equator. The second option causes much larger radii, shorter lifetime and lower radiative impact. However, it should be noted that results of our and other previous studies may suffer from neglecting the microphysical process taking place on small spatial and temporal scales during the injection. The use of an interactively coupled aerosol and general 


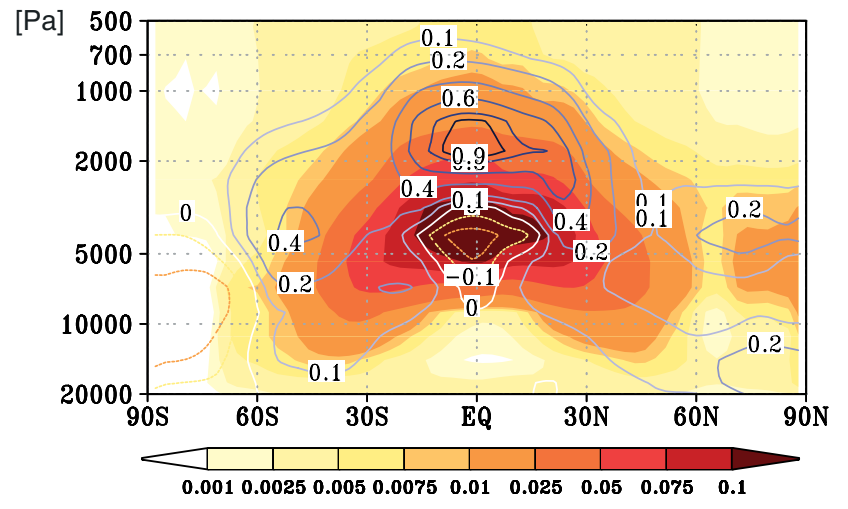

Figure 5. Difference of sulfate concentration (ppb) of a simulation with aerosol coupled to radiation calculations and without the coupling. Underlying are heating rates (K/day) for $4 \mathrm{Mt}(\mathrm{S}) / \mathrm{y}$ at $60 \mathrm{hPa}$.

circulation model has allowed us to study the dynamical feedback on the aerosol cloud resulting from the additional heating. According to our results, this effect is significant but small. Hence, one can assume that the error made in earlier studies through the use of non-interactive coupling is relatively small.

Some additional model deficiencies might influence our results. We have used a coarse grid version of MAECHAM5 that does not simulate a quasi-biennial oscillation (QBO). Hence, the impact of different QBO phases on the transport of the aerosol cloud (Punge et al., 2009) is not taken into account. As our model neglects the stratospheric ozone chemistry, the effect of possible ozone changes on radiation are also missing.

Our study shows that radiative forcing of geoengineered sulfate aerosols depends strongly on the emission strategy. The design of our study, however, does not allow an assessment of possibly important side effects of this geoengineering technique. To study, in particular, the associated ozone depletion and a possible change in precipitation patterns, long ensemble simulations with climate models incorporating a comprehensive representation of chemistry and aerosol microphysical processes would be needed. A scientific consensus on these side effects is still to be reached and very likely requires further fundamental progress in climate research.

\section{Acknowledgements}

The research leading to these results has received funding from the European Union Seventh Framework Programme FP7/2007-2013 under grant agreement no. 226567 (IMPLICC). C. Timmreck is partially supported by the German Research Foundation's Collaborative Research Center 574. Simulations have been performed at the German Climate Computing Centre (DKRZ).

\section{References}

Ansmann A, Mattis I, Wandinger U, Wagner F, Reichardt J. 1997. Evolution of the Pinatubo aerosol: Raman lidar observations of particle optical depth, effective radius, mass and surface area over central Europe at $53.4^{\circ} \mathrm{N}$. Journal of Atmospheric Sciences 54: 2630-2641.

Budyko MI. 1977. Climatic Change. AGU: Washington, DC; 261.

Crutzen PJ. 2006. Albedo enhancement by stratospheric sulfur injections: a contribution to resolve a policy dilemma? Climatic Change 77: 211-219.

Giorgetta MA, Manzini E, Roeckner E, Esch M, Bengtsson L. 2006. Climatology and forcing of the quasi-biennial oscillation in the MAECHAM5 model. Journal of Climate 19: 3882-3901.

Heckendorn P, Weisenstein D, Fueglistaler S, Luo BP, Rozanov E, Schraner M, Thomason LW, Peter T. 2009. The impact of geoengineering aerosols on stratospheric temperature and ozone. Environmental Research Letters 4: 045108. DOI: 10.1088/17489326/4/4/045108.

IPCC. 2007. Summary for policymakers. In: Climate Change. 2007. The Physical Science Basis. Contribution of Working Group I to the Fourth Assessment Report of the Intergovernmental Panel on Climate Change, Solomon S, Qin D, Manning M, Chen Z, Marquis M, Averyt KB, Tignor M, Miller HL (eds). Cambridge University Press: Cambridge, United Kingdom; 996.

Kokkola H, Hommel R, Kazil J, Niemeier U, Partanen A-I, Feichter J, Timmreck C. 2009. Aerosol microphysics modules in the framework of the ECHAM5 climate model - intercomparison under stratospheric conditions. Geoscientific Model Development 2: 97-112. http://www.geosci-model-dev.net/2/97/2009/gmd-2-972009.html [Accessed September 2010].

Niemeier U, Timmreck C, Graf H-F, Kinne S, Rast S, Self S. 2009. Initial fate of fine ash and sulfur from large volcanic eruptions,. Atmospheric Chemistry and Physics 9: 9043-9057. http://www.atmos-chem-phys.net/9/9043/2009/acp9-9043-2009.html [Accessed September 2010].

Pierce J, Weisenstein D, Keith D. 2010. Efficient formation of stratospheric aerosol for geoengineering through emission of lowvolatility vapours in an aircraft plume. Geophysical Research Abstracts 12: EGU2010-12389.

Punge HJ, Konopka P, Giorgetta MA, Müller R. 2009. Effects of the quasi-biennial oscillation on low-latitude transport in the stratosphere derived from trajectory calculations. Journal of Geophysical Research 114: D03102. DOI: 10.1029/2008JD010518.

Rasch PJ, Crutzen PJ, Coleman DB. 2008. Exploring the geoengineering of climate using stratospheric sulfate aerosols: the role of particle size. Geophysical Research Letters 35: L02809. DOI: 10.1029/2007GL032179.

Robock A, Marquardt AB, Kravitz B, Stenchikov G. 2009. The benefits, risks, and costs of stratospheric geoengineering. Geophysical Research Letters 36: L19703. DOI: 10.1029/2009GL039209.

Robock A, Oman L, Stenchikov G. 2008. Regional climate responses to geoengineering with tropical and Arctic SO2 injections. Journal of Geophysical Research 113: D16101. DOI: 10.1029/2008JD010050.

Roeckner E, Brokopf R, Esch M, Giorgetta MA, Hagemann S, Kornblueh L, Manzini E, Schlese U, Schulzweida U. 2006. Sensitivity of simulated climate to horizontal and vertical resolution in the ECHAM5 atmosphere model. Journal of Climate 19: 3771-3791.

Tilmes S, Garcia RR, Kinnison DE, Gettelman A, Rasch PJ. 2009. Impact of geoengineered aerosols on the troposphere and stratosphere. Journal of Geophysical Research 114: D12305. DOI: 10.1029/2008JD011420.

Tilmes S, Müller R, Salawitch R. 2008. The sensitivity of polar ozone depletion to proposed geoengineering schemes. Science 320(5880): 1201-1204. DOI: 10.1126/science.1153966.

Stier P, Feichter J, Kinne S, Kloster S, Vignati E, Wilson J, Ganzeveld L, Tegen I, Werner M, Balkanski Y, Schulz M, Boucher O, Minikin A, Petzold A. 2005. The aerosol-climate model ECHAM5-HAM,. Journal of Atmospheric Chemistry 5: 1125-1156.

Vignati E, Wilson J, Stier P. 2004. M7: an efficient size resolved aerosol microphysics module for large-scale aerosol transport models. Journal of Geophysical Research 109: D22202. DOI: 10.1029/2003JD004485. 